\title{
Mitochondrial transfer: Ethical, legal and social implications in assisted reproduction
}

\author{
A S Reznichenko, ${ }^{1,2}$ MSc; C Huyser, ${ }^{1} \mathrm{PhD} ;$ M S Pepper, ${ }^{2} \mathrm{MB}$ ChB, PhD, MD \\ ${ }^{1}$ Department of Obstetrics and Gynaecology, Steve Biko Academic Hospital, University of Pretoria, South Africa \\ ${ }^{2}$ Department of Immunology and Institute for Cellular and Molecular Medicine, Faculty of Health Sciences, University of Pretoria, South Africa
}

Corresponding author: A S Reznichenko (sashrez@gmail.com)

\begin{abstract}
Diseases resulting from mutations in mitochondrial DNA (mtDNA) are inherited by all offspring through the maternal lineage. Multiple organs are severely affected, no preventative treatments are available and most patients experience a poor quality of life or early death. With developments in mitochondrial transfer techniques, hope for preventing transmission of mutated mtDNA onto offspring is emerging. Many ethical issues have been raised regarding such treatments, which involve transfer of nuclear material into donated oocytes with healthy mitochondria, or the introduction of healthy donor mitochondria into affected oocytes. Blastomere, ooplasmic, pronuclear and spindle transfer have been explored. Ethical concerns relate to (a) the alteration of germ line genetics and (b) the dilemma of children inheriting DNA material from three instead of two parents. In contrast to gene therapy, where only the DNA of the treated individual is altered, these techniques involve the introduction of foreign mtDNA into the germ line that will be inherited by all children in downstream generations. Mitochondrial transfer has also been closely associated with reproductive cloning, which is regulated differently worldwide. Children born from these techniques might experience an identity crisis. Although three gametes are needed to produce a healthy embryo in this scenario, the child will inherit all nuclear DNA from the intending parents, while only inheriting mtDNA from the donor. Social and scientific values must be considered when introducing new healthcare technology. Many believe that some assisted reproductive technology techniques go beyond the limits of acceptable medical intervention. But who ultimately decides what is acceptable? We address the ethical and social issues surrounding this emerging new technology, legal developments regarding its clinical introduction in the UK and the USA, the future impact on technique and patient management, and relevant legislation in South Africa.
\end{abstract}

S Afr J BL 2015;8(2 Suppl 1):32-35. DOI:10.7196/sajbl.8002

Mitochondrial DNA (mtDNA) diseases are inherited maternally by both male and female offspring, since all mitochondria are derived from the oocyte cytoplasm. ${ }^{[1]}$ Most symptoms result in severe disability as the muscles, heart and other vital organs, which require high cellular energy production, are heavily affected. Currently, treatments for such syndromes are limited and supportive, aiming to hinder progression of the disease, rather than restorative. ${ }^{[2]}$ The most severely affected patients die very young having lived a very poor quality of life. ${ }^{[3,4]}$ Alternative therapies are needed, including those which are preventative. However, with developments in mitochondrial transfer techniques many ethical issues have been raised in the health and public sectors regarding these novel treatment options.

Many papers have provided insight into possible cures for human mtDNA disorders via transfer of nuclear material into donated oocytes with healthy mitochondria, or the introduction of healthy donor mitochondria into the affected oocytes, using assisted reproductive technology (ART) techniques involving micromanipulation. These treatments could potentially prevent transmission of mitochondrial disease from an affected or carrier mother to her offspring. Spindle ${ }^{[5]}$ and ooplasmic transfer ${ }^{[6,7]}$ pre-fertilisation, and pronuclear ${ }^{[8]}$ and blastomere nucleus transfer ${ }^{[9]}$ post-fertilisation, have been explored to achieve this. Data from primate and human oocytes have shown spindle (Fig. 1a) and pronuclear transfer (Fig. 1b) to be the most viable thus far. ${ }^{[5,8,10-12]}$ We address the ethical concerns that surround these concepts, discuss the legal positions in the UK, USA and South Africa, and propose the future clinical management of these techniques.

\section{Alteration of germ line genetics}

Mitochondrial transfer has been closely associated with reproductive cloning because these technologies involve alteration of germ line genetics. Unlike gene therapy, in which only the DNA of the individual subjected to the treatment will undergo changes, these novel techniques involve the introduction of foreign mtDNA (from the donor oocyte) into the germ line, which will be inherited by offspring in later generations. A valid argument countering this concern is the fact that ooplasmic transfer has been applied clinically and given rise to the birth of several children. ${ }^{[6,7,13]}$ Consequently, offspring of these female children can have completely different mtDNA make-up, especially if the bottleneck effect results in donor mtDNA comprising the higher proportion of total mtDNA in their oocytes. This means that there will be mostly donor mtDNA expansion in the embryo, and therefore subsequent generations. Surprisingly, to date, no long-term follow-up studies have been conducted on these children. ${ }^{[14]}$

Regarding cloning concerns, which are often associated with mitochondrial transfer, reproductive adult cloning must be distinguished from reproductive embryo cloning. Adult cloning involves the transfer of adult (diploid) nuclear material into an enucleated oocyte. In contrast, the cell to be transferred in embryo cloning originates from an embryo. ${ }^{[15]}$ The latter implies that the 


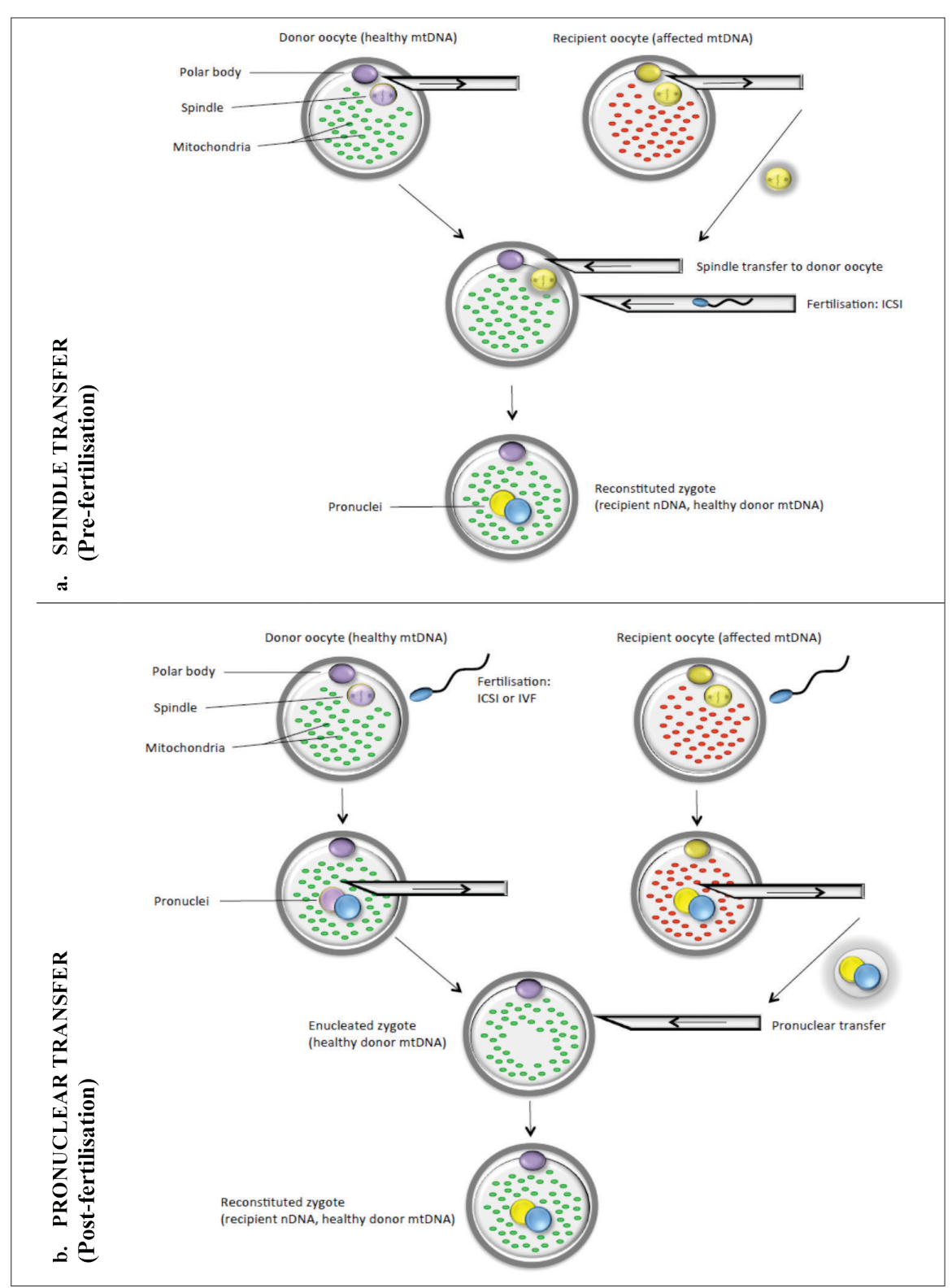

Fig. 1. Spindle(a) and pronuclear(b) transfer techniques.

$I C S \mid=$ intracytoplasmic sperm injection. $m t D N A=$ mitochondrial $D N A . n D N A=$ nuclear $D N A . I V F=$ in vitro fertilisation.

resulting child will be the first of its kind and not a clone of an already existing human. However, many from the professional health and public sectors reject this technology. Internationally, there are differing bioethical and legal regulations concerning human cloning (for reproductive, therapeutic and research purposes). A report in $2006^{[16]}$ summarised these regulatory approaches from 16 countries. Cloning concerns are especially applicable to the blastomere nuclear transfer technique, where a blastomere is derived from an embryo that consists of several cells, not just a single cell as found during transfer of spindles or pronuclei (Fig. 1). Potentially, several blastomeres could be transferred to several enucleated oocytes and give rise to genetically identical offspring. The blastomeres of a single embryo could be used on different occasions resulting in 'delayed' twins. ${ }^{[17]}$ This could be avoided by using one embryo per recipient oocyte, or one embryo per cycle. Alternatively, a multiple embryo transfer can be performed if multiple blastomeres of a single embryo are used for multiple recipient oocytes. Additionally, a completely new cycle could be initiated for each potential pregnancy. ${ }^{[1]]}$ The approach would be unique to each patient, depending on how many embryos are available and how many resultant embryos survive and implant.

\section{Is 'three-parent IVF' a sensationalised term?}

The second ethical issue is the dilemma of children inheriting DNA material from three instead of two parents. The prevention of mtDNA disease transmission has been dubbed 'three-parent IVF'. The general public have been led to believe that this will cause psychosocial problems for children born from these techniques, as they might experience an identity crisis. Three gametes are needed to produce a healthy embryo in this scenario. However, a crucial point is that the child will inherit all nuclear DNA from the intending parents, while only inheriting the mtDNA from the donor. Mitochondrial DNA possesses less than 30 genes, while nuclear DNA encodes approximately 25000 genes. Furthermore, mtDNA is highly conserved among humans (Professor Douglas C. Wallace, University of Pennsylvania, personal communication), and to an extent across species, as mitochondrial energy production is a universal function required by all living organisms. By scale of quantity (number of genes) and quality (gene function), it is misleading for a resultant child to be led to believe that its physical attributes are derived from three, not two, sets of parental DNA. ${ }^{[18]}$

On the other hand, it can be questioned whether some phenotypic characteristics are highly accounted for by the mtDNA physical strength or sports ability, for instance. Unfortunately, such an argument is not applicable in a clinical setting where a couple is unable to have a healthy child that can live to adulthood. Their primary concern is not whether their child will inherit the best mitochondria possible to become an olympic athlete. Furthermore, it has not been proven whether physical strength can be attributed to specific variants of mtDNA genes, mtDNA mutations with an evolutionary advantage, or number of mtDNA copies. Perhaps, physical ability is only partially or completely unrelated to the sequence or natural reserve of mtDNA. Nuclear genes and physical practice could be more responsible for this phenotype.

Other kinship forms that challenge the argument of loss of identity in children with 'three' parents include adoption, surrogacy and use of donor gametes (sperm or oocytes alike) or gestational carriers. Such children could experience the same psychosocial issues. ${ }^{[18]}$ While not possessing DNA from three parents, they have the potential to experience a crisis in terms of how they fit into their families, as in 
theory they have more than two biological and social parents. Applying this sensationalism on a broader scale, would children born through embryo donation then have four parents? Nevertheless, researchers have suggested that if a paternal female relative is available and willing to donate oocytes for the mitochondrial transfer treatment, offspring will inherit paternal mtDNA and all nuclear DNA of the intending parents. Thereby the child will theoretically not possess any 'foreign' DNA from a third party. ${ }^{\left[{ }^{[9]}\right.}$ Additionally, excluding adoption, all cases have a genetic aspect involved. Use of donor gametes and surrogate mothers, of course, result in a complete difference of genetic material between the child and one of the intending parents, causing them to be biologically unrelated. With regard to the use of surrogacy or a gestational carrier, the development of the fetus does not take place in the intending mother's uterus. This alteration of the developmental environment causes epigenetic alterations in the fetal DNA. In this way, the woman that carries the child makes an indirect genetic contribution to the child since epigenetic DNA changes do modify the child's phenotype and can even cause disease. ${ }^{[19]}$

On the grounds that adoption, fostering, step-parenting, surrogacy, and gamete donation are widely accepted in society today, the use of mitochondrial donors is only an extension of current forms of kinship. It seems unlikely that individuals born by these novel procedures would experience more or any psychosocial issues. Researchers conducting evaluations of donor conceived children consider that persons born through mitochondrial transfer techniques would better fit into the category of naturally conceived children, than donor conceived children, when it comes to their psychological wellbeing. ${ }^{[20]}$ The mitochondrial donor should not necessarily be regarded as a second mother or parent to the resulting child, as this is refutable on both biological and legal principles ('Mater semper certa est'). There is also evidence that individuals usually cope quite well with information regarding their origins (be they genetic, biological and/or social) provided that they are told at a relatively young age (during their pre- or primary school years) and in a controlled manner. ${ }^{[2]}$ It is probably advisable for children born by preventative mtDNA disease techniques to be informed at an early age, and that this is reported to them with sufficient information about the procedures and relatively small genetic contribution from the donor.

\section{Future management}

The Nuffield Council on Bioethics of the United Kingdom (UK) ${ }^{[22]}$ has reviewed the novel micromanipulation techniques, which can be utilised for the prevention of mtDNA disorders. The report concluded no overall ethical objection to the use of these technologies in humans for treatment of mtDNA disease, although further investigation is needed to confirm the safety of the techniques. They also recommend that patients are provided with appropriate information and support before and throughout the treatment. Suitably trained and updated individuals should deliver information to prospective patients.

To broaden our knowledge and monitor the outcome of these therapies, the Nuffield Council also advises follow-up and assessment of the resulting children. In terms of regulation, other recommendations also stipulate that the status of mitochondrial donors should differ from oocyte or embryo donors and their identity need not necessarily be disclosed to the children once they reach adulthood. ${ }^{[22]}$ This could potentially be a positive feature of this type of donation and result in more women being willing to donate their oocytes for these treatments, as the legalities of gamete donation can discourage some persons from donating. In 2014 the UK government proposed change in legislation to grant mitochondrial donors anonymity. ${ }^{[23]}$

The Food and Drug Administration (FDA) of the USA, in February 2014, discussed drafting guidelines for the design of clinical trials, but has not published the final document. It was acknowledged that clinical research would also be needed for validation of mitochondrial replacement to treat female infertility. The committee agreed on inclusion criteria for participants and the use of 'historical controls'. Manufacturing controls and quality assessment of techniques, and how these factors could contribute to risk reduction for the participants and their future children, were also discussed. The FDA Cellular, Tissue and Gene Therapies Advisory Committee concluded that currently there is a lack of animal data to commence human clinical trials. Some members suggested additional research in alternative animal species concurrently as no single model emulates human physiology. Aspects to be considered in these studies to supplement current data include:

- Sufficient subject numbers

- Evaluation from embryonic to postnatal stages

- Follow-up (including analysis of neurologic, cardiopulmonary and motor function)

- Assessment of the redox state

- Mitochondrial carryover

- Adverse nuclear-mitochondria interaction.

Other concerns raised included risks to the fetus and resulting children, many of which mirrored those in the UK report. Additionally, the committee reviewed the ethics of participation of these future children in clinical trials without informed consent. The FDA recommends setting up 'centres of excellence' in order to achieve standardisation of mitochondrial manipulation methods. ${ }^{[24]}$

Undoubtedly, mitochondrial replacement therapy has a worthy place in assisted reproduction in the near future, as its benefit outweighs the associated ethical issues. Safety and efficacy must be optimised before human use but there is hope for families that want to prevent transmission of a mitochondrial disorder to their offspring. When developing a new medical therapy one needs to consider first and foremost alleviation of suffering to the patients and their families.

\section{Genetic manipulation in South Africa}

The South African National Health Act 61 of 2003 (NHA), Chapter 8: 'Control of use of Blood, Blood Products, Tissue and Gametes in Humans' ${ }^{[25]}$ states:

'A person may not -

(a) manipulate any genetic material, including genetic material of human gametes, zygotes or embryo; or

(b) engage in any activity, including nuclear transfer or embryo splitting, for the purpose of the reproductive cloning of a human being.'

The document further defines 'reproductive cloning of a human being' as: 'the manipulation of genetic material in order to achieve the reproduction of a human being and includes nuclear transfer or embryo splitting for such purpose.'

The NHA does not mention alteration of germ line genetics or reproductive embryo cloning. Transfer of mtDNA even in the form of blastomere nuclei (the technique which has been scrutinised the 
most by ethicists) is not 'reproductive cloning of a human being'. The document also does not specify that genetic material may not be manipulated for any other reasons. Does this mean that one could undertake mitochondrial transfer in the realms of the South African legal context? It is likely that ministerial authorisation will be required.

\section{Concluding remarks and perspectives}

Both the social and scientific aspects of a new healthcare technology must be considered. Regarding social and moral principles, many believe that some ART techniques go beyond the border of acceptable medical intervention. It is reasonable that these opinions should be considered, but who decides on what is globally acceptable and what is not? Diverse social, ethical, religious, cultural, political, scientific and clinical bodies will have differing attitudes. Public opinion can also make a difference today, more than it could in the past. However, is the public aware of techniques that have been in place for decades in assisted reproduction technology, without appropriate evidence-based data being gathered before implementation? The introduction of novel germ line therapies into humans has proved how important it is for the gap between scientific fact and public opinion to be overcome. The Nuffield Council on Bioethics has achieved this through a comprehensive review of the issues surrounding prevention of mtDNA disease by examining the techniques from many angles. The report also highlighted how some features of the therapies do not truly deviate from what is already considered socially acceptable. ${ }^{[22]}$ However, once mitochondrial transfer becomes available to patients, long-term follow-up monitoring of the resultant children born by these techniques must be performed.

The UK Department of Health has published draft regulations for new techniques to prevent the transmission of mitochondrial disease. ${ }^{[26]}$ These regulations suggest creation of a national or worldwide database that can easily be accessed to encourage information sharing of patient data and improvement and optimisation of the techniques. The UK parliament has debated mitochondrial transfer since 2012 $2^{[27,28]}$ and in February 2015 finally voted in favour of human mitochondrial replacement legalisation to allow the commencement of human clinical application. These Human Fertilisation and Embryology (Mitochondrial Donation) Regulations 2015 will apply from 29 October 2015. ${ }^{[29]}$

With regard to South African legislation, ${ }^{[25]}$ alteration of germ line genetics and cloning other than reproducing human beings is not mentioned, and it is not clear whether the lack of information on these techniques implies that they are not prohibited.

Funding. This research and the publication thereof is the result of funding provided by the Medical Research Council of South Africa in terms of the MRC's Flagships Awards Project SAMRC-RFA-UFSP-01-2013/ STEM CELLS.

\section{References}

1. Giles RE, Blanc H, Cann HM, Wallace DC. Maternal inheritance of human mitochondrial DNA. Proc Natl Acad Sci U S A 1980;77(11):6715-6719. [http:// dx.doi.org/10.1073/pnas.77.11.6715]

2. Pfeffer G, Majamaa K, Turnbull DM, Thorburn D, Chinnery PF. Treatment for mitochondrial disorders. Cochrane Database Syst Rev 2012;4:CD004426. [http:// dx.doi.org/10.1002/14651858.cd004426.pub3]

3. DiMauro S, Schon EA. Mitochondrial respiratory-chain diseases. N Engl J Med 2003; 348(26):2656-2668. [http://dx.doi.org/10.1056/nejmra022567]

4. Schapira AHV. Mitochondrial disease. Lancet 2006;368(9529):70-82. [http:// dx.doi.org/10.1016/s0140-6736(06)68970-8]

5. Tachibana M, Sparman M, Sritanaudomchai $H$, et al. Mitochondrial gene replacement in primate offspring and embryonic stem cells. Nature 2009;461 (7262):367-372. [http://dx.doi.org/10.1038/nature08368]
6. Cohen J, Scott R, Alikani M, et al. Ooplasmic transfer in mature human oocytes. Mol Hum Reprod 1998;4(3):269-280. [http://dx.doi.org/10.1093/molehr/4.3.269]

7. Barritt J, Willadsen S, Brenner C, Cohen J. Cytoplasmic transfer in assisted reproduction. Hum Reprod Update 2001;7(4):428-435. [http://dx.doi. org/10.1093/humupd/7.4.428]

8. Craven L, Tuppen HA, Greggains GD, et al. Pronuclear transfer in human embryos to prevent transmission of mitochondrial DNA disease. Nature 2010;465(7294):8285. [http://dx.doi.org/10.1038/nature08958]

9. Roberts RM. Prevention of human mitochondrial (mtDNA) disease by nucleus transplantation into an enucleated donor oocyte. Am J Med Genet 1999;87(3): 265-266. [http://dx.doi.org/10.1002/(sici)1096-8628(19991126)87:3\%3C265::aidajmg14\%3E3.0.co;2-s]

10. Craven L, Elson JL, Irving L, et al. Mitochondrial DNA disease: New options for prevention. Hum Mol Genet 2011;20(R2):R168-174. [http://dx.doi.org/10.1093/hmg/ddr373]

11. Tachibana M, Sparman M, Mitalipov S. Chromosome transfer in mature oocytes. Fertil Steril 2012;97(5):e16. [http://dx.doi.org/10.1038/nprot.2010.75]

12. Tachibana M, Amato $P$, Sparman $M$, et al. Towards germline gene therapy of inherited mitochondrial diseases. Nature 2013;493(7434):627-631. [http://dx.doi. org/10.1038/nature11647]

13. Barritt JA, Brenner CA, Malter HE, Cohen J. Mitochondria in human offspring derived from ooplasmic transplantation. Hum Reprod 2001;16(3):513-516. [http://dx.doi.org/10.1093/humrep/16.3.513]

14. Krimsky S. Is ooplasm transfer safe for the offspring? Adapted from testimony submitted to the FDA's Cellular, Tissue, and Gene Therapies Advisory Committee. GeneWatch 2014;27(3):22-23.

15. Bredenoord AL, Pennings G, de Wert G. Ooplasmic and nuclear transfer to prevent mitochondrial DNA disorders: Conceptual and normative issues. Hum Reprod Update 2008;14(6):669-678. [http://dx.doi.org/10.1093/humupd/dmn035]

16. Isasi RM, Knoppers BM. National regulatory frameworks regarding human cloning for reproductive and therapeutic/research purposes: A report for the genetics and public policy center, 2006. http://www.dnapolicy.org/pdf/cloning. pdf (accessed 22 January 2015).

17. Bredenoord AL, Dondorp W, Pennings G, De Wert G. Nuclear transfer to prevent mitochondrial DNA disorders: Revisiting the debate on reproductive cloning. Reprod Biomed Online 2011;22(2):200-207. [http://dx.doi.org/10.1016/j.rbmo.2010.10.016]

18. Briscoe R. Ethical considerations, safety precautions and parenthood in legalising mitochondrial donation. New Bioeth 2013;19(1):2-17. [http://dx.doi.org/10.1179 /2050287713z.00000000027]

19. Monk C, Spicer J, Champagne FA. Linking prenatal maternal adversity to developmental outcomes in infants: The role of epigenetic pathways. Dev Psychopathol 2012;24(4):1361-1376. [http://dx.doi.org/10.1017/s0954579412000764]

20. Golombok S. Presentation to the Nuffield Council's Working Group: Fact-finding meeting. Centre for Family Research, University of Cambridge, 2012.

21. Blake L, Casey P, Readings J, Jadva V, Golombok S. 'Daddy ran out of tadpoles': how parents tell their children that they are donor conceived, and what their 7-year-olds understand. Hum Reprod 2010;25(10):2527-2534. [http://dx.doi. org/10.1093/humrep/deq208]

22. Nuffield Council on Bioethics. Report - Novel Techniques for the prevention of mitochondrial DNA disorders: An ethical review. London: Nuffield Council of Bioethics, 2012:52-90.

23. Macrae F. Third parent in IVF cases will not be named: Britain to allow triple-donor embryos to halt genetic diseases in world first - but extra mother's identity will be kept secret. Daily Mail Online News, 2014. http://www.dailymail.co.uk/news/article-2877667/ UK-proposes-rules-embryos-3-people.html (accessed 23 January 2015).

24. Food and Drug Administration. Cellular Tissue and Gene Therapies Advisory committee; Meeting minutes. United States of America 2014. http://www.fda.gov/ AdvisoryCommittees/CommitteesMeetingMaterials/BloodVaccinesandOtherBiologics/ CellularTissueandGeneTherapiesAdvisoryCommittee/ucm380047.htm (accessed 25 January 2015).

25. Republic of South Africa. National Health Act 61. Pretoria: Government Gazette 2003. http://www.acts.co.za/national-health-act-2003/ (accessed 23 January 2015).

26. United Kingdom. Department of Health. https://www.gov.uk/government/ uploads/system/uploads/attachment_data/file/285251/mitochondrial_donation_ consultation_document_24_02_14_Accessible_V0.4.pdf. (accessed 26 January 2015).

27. Barber S, Border P. United Kingdom Parliament. Mitochondrial donation. Standard Note: SN/SC/6833. London: House of Commons Library. 2015. http:// www.parliament.uk/business/publications/research/briefing-papers/SN06833/ mitochondrial-donation (accessed 23 January 2015).

28. Human Fertilisation and Embryology Authority. Mitochondrial donation: An introductory briefing note:October 2014. London: Human Fertilisation and Embryology Authority, 2014. http://www.hfea.gov.uk/docs/2014-10-01_Mitochondrial_ donation_an_introductory_briefing_note_-_final.pdf (accessed 23 January 2015).

29. The Stationery Office Limited. Statuary Instruments 2015 No. 572: Human Fertilisation and Embryology (Mitochondrial Donation) Regulations 2015. London: The Stationery Office Limited, 2015. http://www.legislation.gov.uk/ uksi/2015/572/pdfs/uksi_20150572_en.pdf (accessed 20 May 2015). 